\title{
Influence of Obestatin and Short-Term Treadmill Exercise on Plasma Acyl-Ghrelin and Body Weight in Wistar Rat
}

\author{
Alireza Lotfi, ${ }^{1}$ Sirvan Atashak, ${ }^{2, *}$ and Mohammad Narimani-Rad ${ }^{1}$ \\ ${ }^{1}$ Department of Exercise Physiology, Malekan Branch, Islamic Azad University, Malekan, Iran \\ ${ }^{2}$ Department of Exercise Physiology, Mahabad Branch, Islamic Azad University, Mahabad, Iran \\ "Corresponding author: Sirvan Atashak, Department of Exercise Physiology, Mahabad Branch, Islamic Azad University, Mahabad, Iran. Tel: +98-9143060782, E-mail: \\ arlotfi@gmail.com
}

Received 2015 December 08; Accepted 2016 October 28.

\begin{abstract}
Background: Related reviews reveal that the impact of obestatin (with or without exercise) on the level of ghrelin has not been investigated. The present study investigates the possible effect of intraperitoneally (IP)-administrated obestatin and short-term exercise on serum acyl-ghrelin and body weight in rats.

Methods: In present experimental study forty-five male rats weighing $100 \pm 5 \mathrm{~g}$ were divided into five groups; Group 1 : control group was normally reared, and did not receive any injections or exercise. Group 2 (placebo) was treated with basal solution ( $50 \mathrm{~mL}$ distilled water). Group 3 was referred to as obestatin group which was subjected to double-injection during the test with obestatin (10 $\mu \mathrm{g}$ obestatin/ rat). Group $4 \mathrm{was}$ known as treadmill group which was subjected to treadmill exercise. Finally, group 5, known as obestatin/treadmill group (OT), was subjected to injection with obestatin and treadmill exercise. The exercise groups were trained for 3 weeks (run at $25 \mathrm{~m} / \mathrm{min}$ for 60 minutes, 5 days/week).The data were analyzed with SPSS software version 16.

Results: Two main parameters include body weight gain and serum acyl-ghrelin was assayed. The results indicate that body weight and ghrelin level in obestatin and OT groups did not significant changes compared with the control group $(\mathrm{P}<0.001)$. However, treadmill group had less ghrelin level was different significantly from control group $(\mathrm{P}<0.0001)$. Also, the treadmill group had the least weight gain $(\mathrm{P}<0.0001)$.

Conclusions: It was found that whereas short-term treadmill exercise significantly reduces serum acyl-ghrelin, IP-administration of obestatin had no significant impact on serum acyl-ghrelin and final body weight. The short-term treadmill exercise reduced weight gain rate. The results of the study indicated that the combination of obestatin injection and treadmill exercise had no significant impact on the measured variables.
\end{abstract}

Keywords: Short-Term Exercise, Obestatin, Ghrelin, Body Weight

\section{Background}

It has been 16 years since ghrelin was discovered in humans and animals [1]. Studies on ghrelin have shown that ghrelin-gene codes other peptides with different regulatory effect, namely obestatin. Studies carried out in the medical college of Stanford University in 2005 led to the discovery of a novel peptide which had rather opposite or antagonistic effect on ghrelin. Indeed, in physiological terms, obestatin is a part of ghrelin system [2]. According to bioinformatics, it is a hormone which can be found via searching in genome sequence of many animals [2]. It has twenty three amino acids in its biochemical structure (Figure 1).

It has been argued that obestatin might have potential effects on weight gain and appetite $[2,3]$. Whereas ghrelin and obestatin have the same bio-molecular origin and are released from the same endocrine cells, their levels are different in blood circulation. That is, the peripheral level of ghrelin is ten to twenty times more than that of obestatin $[2,4]$. Two main functional differences between obestatin and ghrelin have been reported [5]:

\section{- Antagonism of GH-releasing}

- Suppression of ghrelin-induced appetite stimulation

In studies conducted on appetite and energy balance of body, various findings have been reported. As a case in point, Sibilia et al. [6] found that obestatin had an appetitesuppressing impact and a significant role in weight loss. However, some other researchers observed that peripheral obestatin had no impact on appetite or food intake [7]. In another study, Lagaud et al. [8] came to the conclusion that the infusion of obestatin reduced food intake and suppressed body weight gain in rodents.

Moreover, numerous other studies have been conducted on the relationship between obestatin and exercise; Ghanbari-Niaki et al. [9] found that six-week treadmill exercise $(20 \mathrm{~m} / \mathrm{min}$, for 60 hours per day) can cause declines in fundus and intestinal obestatin concentration; however, level of plasma obestatin was unchanged which was attributed to treadmill exercise protocol. In another study on obese rats, Wang et al. [10] found that eight-week treadmill exercise ( $20 \mathrm{~m} / \mathrm{min}, 5 \mathrm{~d} / \mathrm{wk}, 40 \mathrm{~min} /$ day) can decrease hypothalamic obestatin but the plasma obestatin 


\section{MPSGTVCSL LLLGMKLD AMGGSSFLSP EHQRVQQRKE SKKPPAKLQP RALăGKLRPE DGGQAEGAED ELEVRFNAPF DVGIKLSGVQ YQQHSQALG FLQDIREEA XEAPADK

level was unchanged in the trained animals.

A brief review of the related literature reveals that the direct impact of obestatin on the level of plasma ghrelin has not been investigated. This is considered to be a research gap. Furthermore, to the best of the researchers' knowledge, no studies have been carried out on synergy (or non-synergy) impact of obestatin and treadmill exercise on ghrelin levels and other metabolic or physiological indices. Indeed, the present study is intended to address the above-mentioned research gaps.

\section{Objectives}

That is to say, the purpose of this study is to investigate the impact of the peripherally-infused exogenous obestatin and short-term treadmill exercise on plasma ghrelin and body weight in rats (trained and not trained).

\section{Methods}

\subsection{General Condition}

Present study is an experimental work on animal model which purchased from Tabriz University of Medical Sciences. Forty-five male wistar rats weighing $100 \pm 5 \mathrm{~g}$ were selected for the experiments after the confirmation of routine veterinary examinations. Animals were kept from 1 week to 12 hours in a light space and 12 hours in dark lighting conditions. The temperature was kept at $22^{\circ} \mathrm{C}$ as the appropriate temperature for the experiment. During the experiment, all animals were fed standard diet based on the formulated laboratory animals enterprise NirooSahand Co@, Tabriz.

\subsection{Grouping}

As mentioned above, the selected rats were divided into five independent experimental groups (each group or treatment included 9 rats). Full randomization was used in the design of the study (CRD):

- Group 1: control group (C) which was normally reared for two weeks. This group was not treated with injections and exercise.

- Group 2: placebo which was treated with injections at two times during the test with hormone-free $(50 \mathrm{~mL}$ distilled water) solution normally and it was kept without exercise protocol.

- Group 3: Obestatin group which was subjected to injections at two times during the test with obestatin $(50 \mathrm{~mL}$ solution contained $10 \mu \mathrm{g}$ obestatin/ rat). During this period, this group was kept - Group 4: treadmill group which was only subjected to treadmill exercise.

- Group 5: Obestatin and treadmill (OT) group which was subjected to obestatin injection at two times during the test with $50 \mathrm{~mL}$ solution containing $10 \mu \mathrm{g}$ obestatin/ rat and treadmill exercise.

\subsection{Exercise Protocol}

At the beginning, the animals were adapted to the rat treadmill apparatus for four days (5-line motorized-driven treadmill was designed by Technic-Azma Co., Tabriz, Iran). The exercise groups were trained for three weeks using the same training procedure used in Ghanbari-Niaki et al. [11] who referred to it as a short-term treadmill exercise. The rats were forced to run at $25 \mathrm{~m} / \mathrm{min}$ for 60 minutes, 5 days/week (Table 1 ).

\subsection{I.P-Injection Procedure}

Lyophilized powder of obestatin (product no: O0266, Rat obestatin, Sigma-Aldrich Co., USA) was dissolved in dis- 
Table 1. Treadmill Exercise Protocol Used in Present Experiment ${ }^{\mathrm{a}}$

\begin{tabular}{lcc}
\hline $\begin{array}{l}\text { Step (Week of } \\
\text { Protocol) }\end{array}$ & Speed (meter $/$ min.) & $\begin{array}{c}\text { Exercise Duration } \\
(\text { min./ day })\end{array}$ \\
\hline $\mathbf{1}$ & 10 & $10-15$ \\
$\mathbf{2}$ & $15-25$ & $15-60$ \\
$\mathbf{3}$ & 25 & 60 \\
\hline \multicolumn{2}{l}{${ }^{\mathrm{a}}$ Adapted from Ghanbari-Niaki et al., [11]. }
\end{tabular}

tilled water. The solution was injected intra-peripherally in $50 \mathrm{~mL}$ volume containing $10 \mu \mathrm{g}$ obestatin for each rat. In the three-week experimental period, the solution was injected twice, i.e. on the first day and on the seventh day.

\subsection{Data Collection and Data Analysis}

All the rats included in the experiments were weighed before and after the experimental period (treadmill exercise). According to laboratory animal ethics, blood samples were taken from heart after anesthesia. The obtained bloods were centrifuged and the produced serum was analyzed for acylated-ghrelin level by rat ghrelin Elisa kit (Glory kits, Canada).

The collected data was fed into SPSS V.16 for conducting the required statistical analysis. The normality of collected data was analyzed by Kolmogorov-Smirnov test. Then, ANOVA (analysis of variance) was used to statistically examine the significance differences among the independent groups of the study $(\mathrm{P}<0.05)$. Next, tukey post-hoc test was used to detect the direction and location of significant difference among the five independent groups of the study.

\section{Results}

The mean values ( \pm SEM) of ghrelin level and body weight are depicted in Figures 2 and 3, respectively. As illustrated in Figure 2, based on the results of ANOVA test, the obestatin group and OT (obestatin and treadmill) group were not significantly different from the control group. However, it should be noted that the treadmill group was significantly different from the control group. The difference was related to less ghrelin level ( $\mathrm{P}$ $<0.0001$ ). Moreover, as shown in Figure 3, regardless of positive weight gain in all groups, rats within the treadmill protocol (treadmill group) had significantly less weight gain than those of other experimental groups $(\mathrm{P}<0.0001)$. Furthermore, no significant difference was found between obestatin group and OT group.
Figure 2. Plasma Acyl-Ghrelin of Trained and Obestatin Injected Rats

Acyl-Ghrelin, pg/mL

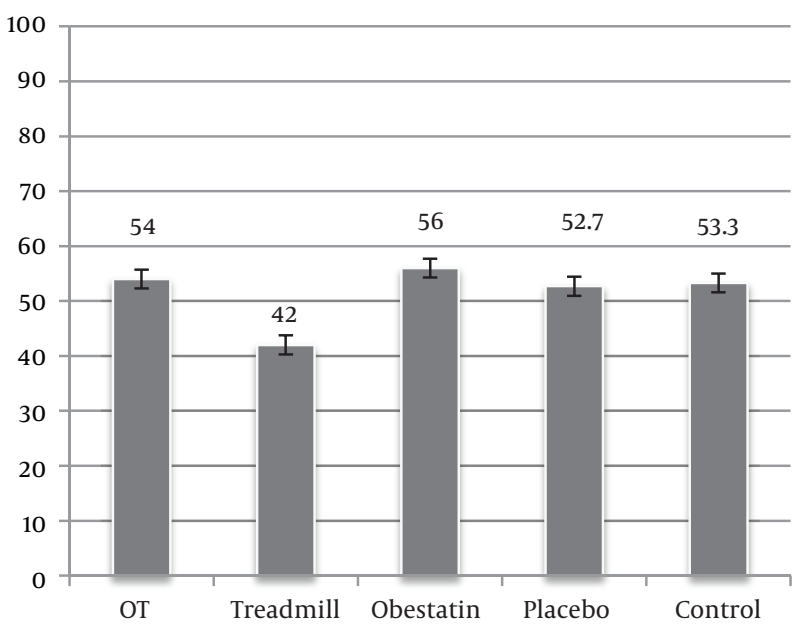

$\mathrm{P}<$ 0.0001, SEM: 0.730; OT: obestatin + treadmill.

Figure 3. Body Weight Gain of Trained and Obestatin Injected Rats

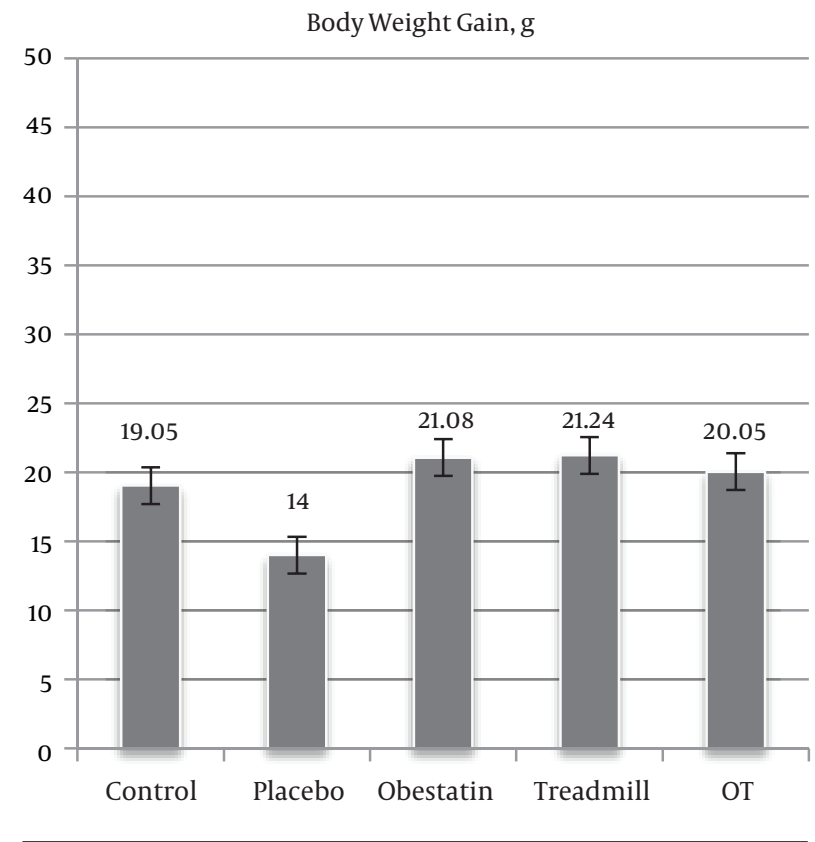

P < 0.0001, SEM: 0.381; OT: obestatin + treadmill.

\section{Discussion}

As it is depicted in Figure 2, the results of the present study revealed that only treadmill exercise led to a significant decline in acyl-ghrelin which was not the case with the rats within other experimental groups. Present study had 
shown that short-term exercise may decrease both acylghrelin and body weight gain parameters in rat model, without any synergic effect of infused-obestatin. The findings of the present study acknowledge those of Hsu et al. [12] and Ghanbari-Niaki et al. [11] who found that exercise in short-term, or in simple training arrangement resulted in a decline in acyl-ghrelin level.

Surprisingly, the group with both treadmill exercise and obestatin injection was not significantly different from the control group. In other words, the infusion of exogenous obestatin had no remarkable impact on the ghrelin level (Figure 2).

Zhang et al. [2] found that daily obestatin injection prevented body weight gain induced by ghrelin after a one-week period. In another study, acute intracerebroventricular-injection of obestatin and ghrelin did not change ghrelininduced increase of food intake in rats [13].

Studies indicating the lack of obestatinimpact on food intake are related to fasted-rodents which is a condition associatedwith the highest endogenous circulating levels of ghrelin [14-16].

It can be argued that obestatin also did not alter theaction of endogenous ghrelin. Obestatin serum levels, unlike those of ghrelin, are not affected by feeding orfasting [2]. In our study (Figure 2) I.P-obestatin infusion had no effect on plasma ghrelin level.

The findings of this study are in line with those of Zhang et al. [2] and Seoane et al. [13], who argued that ghrelin or ghrelin-induced food intake is independent of the impact of obestatin. It can be maintained that high endogenous ghrelin level, unlike infusion of exogenous obestatin, had no effect on serum ghrelin level. This finding corroborates those of Tschop et al. [14], Tolle et al. [15] and Gourcerol et al. [16]. Also, obestatin might co-operate with ghrelin and regulate ghrelin releasing. In contrast, regarding group five (OT) which is illustrated in Figure 2, exercise resulted in a decrease in ghrelin.

Regarding the impact of exercise or training on plasma ghrelin, different findings have been reported depending on training type, its duration, and intensity. In the present study, the findings of the effect of short-term treadmill exercise (Figure 2) acknowledge those of Ghanbari-Niaki et al. [11] for short- or moderate-term exercise. Furthermore, the findings corroborate those of Tiryaki-Sonmez et al. [17] which was conducted on humans.

Zakavi et al. [18] contended that "Pilates Training" for 6-months had resulted in an increase in plasma total ghrelin level. Nevertheless, in simple treadmill exercise (endurance training) a significant decline was reported in plasma ghrelin level not only for rats and humans $[11,17]$.

Studies investigating human ghrelin focused on weight loss more than studying the direct impact of exercise $[19,20]$. Hence, it should be pointed out that the mechanisms by which treadmill endurance training alters plasma ghrelin are not far from knowns and is considered to be a research question.

Ghanbari-Niaki et al. [11] argued that lower plasma ghrelin can be justified and explained by improvements in training-induced exercise in energy status with reserved/available sources such as liver ATP content as well as liver glycogen content. It should be highlighted that ghrelin is a strong signal for mobilization of new food sources to produce energy in body [21]. It should be pointed out that lower plasma ghrelin content might be affected by a negative feedback from higher plasma levels of GH which should be investigated in future studies.

The impact of treadmill exercise on weight loss is evident. In an experiment on laboratory rats, the weight loss rate caused by treadmill exercise did not occur up to 5week from the onset of exercise training. But after week six, the weight loss was more remarkable and obvious due to treadmill exercise [22]. In the study carried out by Mohebbi et al. [22] which was similar to the treadmill protocol in the present study, short-term exercise could not reduce body weight. Similarly in Ghanbari-Niaki et al. [11], the animals did not lose weight through short-term treadmill protocol.

Finding of the present study, as shown in Figure 3, acknowledged those of Ghanbari-Niaki et al. [11] and Mohebbi et al. [22] who did not find any significant impact of short-term treadmill exercise on weight loss. It seems that short-term exercise led to a decrease in the appetite of trained animals which did not bring about remarkable weight loss. Also, it can be attributed to the decreased concentration of peripheral acyl-ghrelin (Figure 2) and other appetite-stimulating peptides which was reported by Tiryaki-Sonmez et al. [17].

In this study, peripheral administration of obestatin ( 5 microgram/ rat) had no effect on the final body weight which is shown in Figure 3. Similarly, Sibilia et al. [6] found that low or moderate dosages of obestatin ( 0.75 and $1.2 \mathrm{mi}$ crogram /rat) had no significant impact on body weight. Moreover, Taghian and Zolfaghari. [23] found no significant correlation between intensity of exercise and peripheral obestatin level.

\subsection{Conclusion}

The concluded to be made based on the findings of this study is that short-term treadmill exercise significantly reduced serum acyl-ghrelin in rats. Nevertheless, IPinjection of obestatin had no significant impact on serum acyl-ghrelin and final body weight. In general, it can be maintained that short-term treadmill exercise reduced the 
rate of weight gain. Furthermore, obestatin injection combined with treadmill exercise did not have notable impact on acyl-ghrelin and body weight in animals. It seems injection of obestatin had no additive or synergy effects in short-term exercises.

Further studies with different dosage of obestatin and different extensities of endurance exercise is suggested.

\section{Acknowledgments}

Present study is summarized from M.Sc. Thesis on exercise physiology, conducted by first author in "Malekan Branch, Islamic Azad University". Authors are thankful to their kind assistance.

\section{Footnotes}

Authors' Contribution: All authors had equal role in design, work, statistical analysis and manuscript writing.

Conflict of Interest: The authors declare no conflict of interest.

Funding/Support: Malekan branch, Islamic Azad University.

\section{References}

1. Kojima M, Hosoda H, Date Y, Nakazato M, Matsuo H, Kangawa K. Ghrelin is a growth-hormone-releasing acylated peptide from stomach. Nature. 1999;402(6762):656-60. doi: 10.1038/45230. [PubMed: 10604470].

2. Zhang JV, Ren PG, Avsian-Kretchmer O, Luo CW, Rauch R, Klein C, et al. Obestatin, a peptide encoded by the ghrelin gene, opposes ghrelin's effects on food intake. Science. 2005;310(5750):996-9. doi: 10.1126/science.1117255. [PubMed: 16284174].

3. Bassil AK, Haglund Y, Brown J, Rudholm T, Hellstrom PM, Naslund E, et al. Little or no ability of obestatin to interact with ghrelin or modify motility in the rat gastrointestinal tract. Br J Pharmacol. 2007;150(1):58-64. doi:10.1038/sj.bjp.0706969. [PubMed: 17128285].

4. Gronberg M, Tsolakis AV, Magnusson L, Janson ET, Saras J. Distribution of obestatin and ghrelin in human tissues: immunoreactive cells in the gastrointestinal tract, pancreas, and mammary glands. J Histochem Cytochem. 2008;56(9):793-801. doi: 10.1369/jhc.2008.951145. [PubMed: 18474938].

5. Hassouna R, Zizzari P, Tolle V. The ghrelin/obestatin balance in the physiological and pathological control of growth hormone secretion, body composition and food intake. I Neuroendocrinol. 2010;22(7):793-804. doi: 10.1111/j.1365-2826.2010.02019.x. [PubMed: 20456603].

6. Sibilia V, Bresciani E, Lattuada N, Rapetti D, Locatelli V, De Luca V, et al. Intracerebroventricular acute and chronic administration of obestatin minimally affect food intake but not weight gain in the rat. J Endocrinol Invest. 2006;29(11):RC31-4. doi: 10.1007/BF03349204. [PubMed: 17259788]
7. Chartrel N, Alvear-Perez R, Leprince J, Iturrioz X, Reaux-Le Goazigo A, Audinot V, et al. Comment on "Obestatin, a peptide encoded by the ghrelin gene, opposes ghrelin's effects on food intake". Science. 2007;315(5813):766. doi: 10.1126/science.1135047. [PubMed: 17289961].

8. Lagaud GJ, Young A, Acena A, Morton MF, Barrett TD, Shankley NP. Obestatin reduces food intake and suppresses body weight gain in rodents. Biochem Biophys Res Commun. 2007;357(1):264-9. doi: 10.1016/j.bbrc.2007.03.138. [PubMed:17418097].

9. Ghanbari-Niaki A, Saghebjoo M, Rahbarizadeh F, Hedayati M, Rajabi H. A single circuit-resistance exercise has no effect on plasma obestatin levels in female college students. Peptides. 2008;29(3):487-90. doi: 10.1016/j.peptides.2007.11.002. [PubMed: 18308154].

10. Wang J, Chen C, Wang RY. Influence of short- and long-term treadmill exercises on levels of ghrelin, obestatin and NPY in plasma and brain extraction of obese rats. Endocrine. 2008;33(1):77-83. doi: 10.1007/s12020-008-9056-z. [PubMed: 18389390].

11. Ghanbari-Niaki A, Jafari A, Moradi M, Kraemer RR. Short-,moderate, and long-term treadmill training protocols reduce plasma, fundus, but not small intestine ghrelin concentrations in male rats. J Endocrinol Invest. 2011;34(6):439-43. doi: 10.3275/7437. [PubMed: 21183796].

12. Hsu YW, Pan YJ, Cho YM, Liou TH, Chou P, Wang PS. Aging effects on exercise-induced alternations in plasma acylated ghrelin and leptin in male rats. Eur J Appl Physiol. 2011;111(5):809-17. doi: 10.1007/s00421010-1704-3. [PubMed: 21046141].

13. Seoane LM, Al-Massadi O, Pazos Y, Pagotto U, Casanueva FF. Central obestatin administration does not modify either spontaneous or ghrelin-induced food intake in rats. J Endocrinol Invest. 2006;29(8):RC13-5. doi: 10.1007/BF03344174. [PubMed: 17033253].

14. Tschop M, Smiley DL, Heiman ML. Ghrelin induces adiposity in rodents. Nature. 2000;407(6806):908-13. doi: 10.1038/35038090. [PubMed: 11057670].

15. Tolle V, Bassant MH, Zizzari P, Poindessous-Jazat F, Tomasetto C, Epelbaum J, et al. Ultradian rhythmicity of ghrelin secretion in relation with $\mathrm{GH}$, feeding behavior, and sleep-wake patterns in rats. Endocrinology. 2002;143(4):1353-61. doi: 10.1210/endo.143.4.8712. [PubMed: 11897692].

16. Gourcerol G, St-Pierre DH, Tache Y. Lack of obestatin effects on food intake: should obestatin be renamed ghrelin-associated peptide (GAP)?. Regul Pept. 2007;141(1-3):1-7. doi: 10.1016/j.regpep.2006.12.023. [PubMed: 17321609].

17. Tiryaki-Sonmez G, Ozen S, Bugdayci G, Karli U, Ozen G, Cogalgil S, et al. Effect of exercise on appetite-regulating hormones in overweight women. Biol Sport. 2013;30(2):75-80. doi: 10.5604/20831862.1044220. [PubMed: 24744470].

18. Zakavi I, Zakavi E, Taghiyan F. Effect of pilates training on plasma levels of ghrelin and obestatin in obese older men (in Persian).J Shahid Sadoughi Univ Med Sci. 2015;23(3):2021-31.

19. Foster-Schubert KE, McTiernan A, Frayo RS, Schwartz RS, Rajan KB, Yasui $Y$, et al. Human plasma ghrelin levels increase during a oneyear exercise program. J Clin Endocrinol Metab. 2005;90(2):820-5. doi: 10.1210/jc.2004-2081. [PubMed: 15585547].

20. Broom DR, Batterham RL, King JA, Stensel DJ. Influence of resistance and aerobic exercise on hunger, circulating levels of acylated ghrelin, and peptide YY in healthy males. Am J Physiol Regul Integr Comp Physiol. 2009;296(1):R29-35. doi: 10.1152/ajpregu.90706.2008. [PubMed: 18987287].

21. McKibben B. Ghrelin: The hunger hormone. Adv Biochem. 2007:1-12.

22. Mohebbi H, Rohani H, Hassan-nia S, Pirooznia N. The Effect of obesity and endurance training-induced weight loss on UCP3 mRNA Expression in C57BL/6 MICE (in Persian). J Endocrinol Metab. 2013;15(3):311-21.

23. Taghian F, Zolfaghari MJ. Effect of 12 week aerobic exercise on the obestatin level in obese women. Jahrom Univ Med Sci. 2014;11(4):1-8. 